\title{
"LIVRO DE DEMARCAÇÕES ENTRE ESTES REINOS E OS DE CASTELA E DE CONTRATOS DE PAZES", UN CARTULARIO PARA LAS RELACIONES LUSOCASTELLANAS EN LA BAJA EDAD MEDIA
}

\author{
"LIVRO DE DEMARCAÇÕES ENTRE ESTES REINOS \\ E OS DE CASTELA E DE CONTRATOS DE PAZES", A \\ CHARTULARY FOR DIPLOMATIC RELATIONS BETWEEN \\ CASTILE AND PORTUGAL IN THE LATE MIDDLE AGES
}

\author{
Néstor VIGIL MONTES \\ Centro Interdisciplinar de História, Culturas e Sociedades (CIDEHUS) \\ Universidade de Évora
}

\begin{abstract}
Resumen: El "Livro de demarcações entre estes reinos e os de Castela e de contratos de pazes" custodiado en el fondo de Leitura Nova del Arquivo Nacional da Torre do Tombo constituye uno de los pocos ejemplos conocidos de cartulario destinado a conservar los documentos referentes a las relaciones entre dos estados. A través del análisis de sus elementos externos (estudio codicológico y paleográfico), de la estructura de su contenido (organización de los documentos en el códice y análisis de las tipologías documentales) y de la biografía de su redactor Fernão de Pina, hemos podido obtener conclusiones sobre el contexto de redacción. Podemos afirmar que fue elaborado con anterioridad al fondo de Leitura Nova que data del siglo XVI, pudiéndose retrotraer a las décadas finales del siglo XV. Esto supone que coincide con un momento de gran intensidad en las relaciones lusocastellanas, pudiendo constituir el precedente inmediato a la elaboración del fondo de Leitura Nova, al que fue incorporado posteriormente. A pesar de la importancia de la pieza documental, apenas ha sido tenido en cuenta en la inmensa bibliografía referente a las relaciones lusocastellanas, por lo que pretendemos acercarla a los medievalistas a través de la edición de los correspondientes regestos.
\end{abstract}

Palabras clave: Cartularios, Diplomática de las relaciones internacionales, Relaciones lusocastellanas en la Baja Edad Media.

\footnotetext{
${ }^{1}$ Este estudio ha sido posible gracias al disfrute de una beca posdoctoral (bolsa de pósdoutoramento) financiada por la Fundação para a Ciência e a Tecnologia do Ministério da Educação e Ciência de Portugal (SFRH/BPD/94257/2013), e inserto dentro del proyecto "DEGRUPE A dimensão europeia de um grupo de poder: o clero e a construção política das monarquias ibéricas (XIII-XV) / The European Dimension of a Group of Power: Ecclesiastics and the political State Building of the Iberian Monarchies (13th-15th centuries)" financiado por fondos nacionales a través de la FCT/MCTES y cofinanciado por los fondos europeos FEDER a través del programa COMPETE (PDTC/EPH-HIS/4964/2012).
} 


\begin{abstract}
The book of frontier demarcations and peace treatments between the kingdom of Portugal and the kingdom of Castile, kept in the "Leitura Nova" collection within the National Archives of Portugal ("Torre do Tombo"), is one of the rare known examples of cartulary destined to preserve documents concerning international relationships between two states. Through the analysis of its external elements (Codicological and paleographical study), the structure of its contents (organization of documents in the codex and the analysis of document typologies), and the biography of its editor, Fernão de Pina; we could draw conclusions about the context of its elaboration. We can assert that it was produced before the rest of the codices of the "Leitura Nova" collection, dating from the sixteenth century, and we can place it in the last decades of the fifteenth century, coinciding with a moment of a great intensity in the Luso-Castilian relations and it may well be the immediate precursor to the preparation of "Leitura Nova" collection, in which it was incorporated later. Despite the importance of this cartulary, it has scarcely been considered in the vast bibliography on the Luso-Castilian relations, therefore we intend to bring it closer to the medievalists across the edition of the summaries of its documents.
\end{abstract}

Keywords: Cartularies, International relations diplomatics, Luso-castilian relations in the late Middle Ages.

\title{
1. INTRODUCCIÓN
}

En el fondo "Leitura Nova" del Arquivo Nacional da Torre do Tombo de Lisboa, se encuentra una excepcional colección de cartularios regios elaborados por orden de D. Manuel I en 1504 con el fin de conservar los documentos más importantes del Arquivo Real. Se trata de un conjunto de 61 códices datados entre 1504 y 1552, y organizados tematicamente y/o geograficamente, con títulos como: livros de direitos reais, de padroados, de forais, de Beira, de Além-Douro... Sin embargo, a pesar de su relevancia para el conocimiento de la historia medieval portuguesa y la disponibilidad de digitalizaciones de libre acceso en el sitio web de la Direcção Geral de Arquivos de Portugal $^{2}$, apenas han sido objeto de estudios ni de ediciones documentales.

Dentro de los cuales ha centrado nuestra atención el llamado "Livro de demarcações entre estes reinos e os de Castela e de contratos de pazes"3, por tratarse de uno de los pocos ejemplos conocidos de cartulario elaborado para las relacio-

2 La digitalización se encuentra en http://digitarq.arquivos.pt/details?id=4223191 [Visto $1 / 3 / 2015]$

${ }^{3}$ Arquivo Nacional da Torre do Tombo (A.N.T.T.), Leitura Nova, livro 61 (livro das pazes). Copia microfilmada (mf. 7514). 
nes internacionales, pretendiendo ampliar aun más si cabe el rico concepto de cartulario ${ }^{4}$.

Nuestro primer objetivo será la elaboración de un estudio formal de la pieza utilizando los métodos codicológico, paleográfico y diplomático ${ }^{5}$, para no solamente obtener un análisis descriptivo de la factura del cartulario, sino también para disponer de indicios sobre cuál sería la función original del códice y su relación exacta con los restantes códices del fondo de Leitura Nova.

Como colofón a esta investigación, se incluyen los regestos de los diferentes documentos que integran el cartulario con el fin de facilitar el acceso a su interesante contenido, que en algunos casos alcanza una importancia capital al constituir el único testigo que se conserva de ciertos documentos.

Con todo este trabajo pretendemos acercar a los historiadores, una pieza imprescindible para el conocimiento de las relaciones lusocastellanas en la Edad Media y más concretamente para el estudio de la que se considera como la primera frontera legalmente delimitada del Occidente Cristiano, un tema que ha sido tratado en diversos artículos ${ }^{6}$, pero del que todavía se podrían obtener nuevas conclusiones si fuesen aprovechados los documentos del presente cartulario, cuyo contenido hasta la fecha ha pasado bastante inadvertido en la mencionada línea historiográfica ${ }^{7}$.

${ }^{4}$ Un buen estado de la cuestión sobre la situación actual en la investigación sobre los cartularios lo tenemos en E. E. RODRÍGUEZ DÍAZ, "Los cartularios en España: Problemas y perspectivas de investigación", La escritura de la memoria: los cartularios, Huelva, 2010, pp. 1336; y en A. SÁNCHEZ MAIRENA, "La investigación sobre los cartularios en España, iniciativas para establecer un marco teórico", en Alma littera, estudios dedicados al profesor José Manuel Ruiz Asencio, Valladolid, 2014, pp. 639-649 (https://www.academia.edu/attachments/35545514/ download_file?s=swp-sidebar).

${ }^{5}$ Con este fin tendremos en cuenta algunas de las recomendaciones de A. SÁNCHEZ MAIRENA, "Propuestas metodológicas para el estudio de los cartularios medievales", Mundos medievales: espacios, sociedades y poder (Homenaje a José Ángel García de Cortázar), vol. I, Santander, 2012, pp. 217-230 (https://www.academia.edu/attachments/31073982/download_file?s=swpsidebar).

${ }^{6}$ Algunos ejemplos son J. L., MARTÍN MARTÍN, "La frontera hispano-portuguesa en la guerra, en la paz y el comercio", en Las relaciones entre Portugal y Castilla en la época de los descubrimientos y la expansión colonial, Salamanca, 1994, pp. 29-51; H. B. MORENO, “A sociedade de fronteira hispano-portuguesa no século XV", en Castilla y Portugal en los albores de la Edad Moderna, Valladolid, 1997, pp. 9-17; M. C. QUINTANILLA RASO, "Consideraciones sobre las fortalezas de la frontera castellano-portuguesa en la Baja Edad Media", en Actas das II Jornadas Luso-Espanholas de História Medieval, vol. I, Lisboa, 1987, pp. 401-430.

${ }^{7}$ El único artículo en el que se aprovecha esta fuente es J. L. MARTÍN MARTÍN, "Conflictos luso-castellanos por la raya”, en As relações de fronteira no século de Alcanices, vol. I, Porto, 1998 , pp. 259-273. 


\section{CARACTERÍSTICAS FÍSICAS DEL CÓDICE}

Lo que va presidir en la factura material del cartulario es la solemnidad, se trata de un manuscrito realizado sin reparar en gastos, cuyo destino final era la preservación de algunos de los documentos más importantes del arquivo real portugués ${ }^{8}$.

A pesar de que el cartulario se conozca como "Livro de demarcações entre estes reinos e os de Castela e de contratos de pazes" o simplemente "Livro das pazes", si somos escrupulosos con la terminología empleada en la codicología, no nos encontramos con un libro, sino con un códice ya que el material empleado es el pergamino. Es un códice de 156 folios (394 x $296 \mathrm{~mm}$ ) distribuidos en cuadernillos compuestos de cinco bifolios (quiniones), a excepción de un ternión añadido a posteriori al comienzo del volumen. El empleo del pergamino era poco frecuente en las cancillerías europeas a finales de la Edad Media, siendo desplazado por el papel que era un material mucho más barato ${ }^{9}$, reservándose únicamente para los instrumentos más importantes.

Ante tales pretensiones de solemnidad, la pobre encuadernación actual del códice parece ser un detalle disonante. La explicación a este hecho es que no se trata de la original, sino de una moderna más propia de los siglos XIX-XX, y es que los archiveros tendían a sustituir las encuadernaciones originales deterioradas para favorecer la conservación del resto del manuscrito, además generalmente lo hacían a gran escala abarcando fondos al completo. Por ello todos los códices del fondo Leitura Nova comparten una austera encuadernación moderna como formato homogeneo.

En cuanto a la ejecución del manuscrito observamos una cuidadosa preparación de la superficie de escritura con un pautado que establecía el tamaño de la caja de texto, determinaba las líneas de escritura y reservaba un espacio para la foliación en números romanos en el margen superior del recto de cada folio. Los márgenes empleados tienen un gran tamaño (a excepción de los laterales interiores) como era propio de códices solemnes. Tampoco se descuidaba la preparación del códice en su conjunto con la utilización de pequeñas llamadas al final de cada cuadernillo de pergamino destinadas para garantizar que se respetase el orden en

${ }^{8}$ Ostentación y conservación son dos de lo denominadores comunes de los cartularios así como señala C. SAEZ, "Origen y función de los cartularios hispanos", Anuario del Centro de Estudios Históricos Prof. Carlos S. A. Segreti, 5 (2005), pp. 37-48 (http://dialnet.unirioja.es/ descarga/articulo/3740365.pdf).

${ }^{9}$ P. PUIG USTRELL, Los pergaminos, ¿Qué son y cómo se tratan?, Gijón, 2008, p. 21. 
el proceso de encuadernación, en este caso limitadas a la inclusión de la primera palabra del siguiente cuaderno dentro de la rúbrica de Fernão de Pina, que aparece en el margen inferior de todas las caras del códice como testigo de quien fue el responsable de su redacción.

Para la redacción del contenido se empleó una escritura de enorme solemnidad como era la littera textualis o gótica textual ${ }^{10}$ con detalles propios de la etapa redonda, la propia de los siglos XV-XVI que se desarrolló sobre todo en el ámbito luso-castellano, como son los trazados más redondos o el empleo de las "d" unciales ${ }^{11}$. A pesar de lo pausado de la escritura que se ejecuta en un pautado, el escribano no tiende a desarrollar las abreviaturas reproduciendo la redacción original de los documentos como sucede en muchos otros cartularios ${ }^{12}$, y comete constantes errores de omisión de contenido que son subsanados con llamadas a cajas de texto que se ejecutaron en el margen lateral exterior a la altura de donde se cometió el fallo. A diferencia de los otros códices de la Leitura Nova que siguen la distribución a dos columnas tan propia de la redacción de los cartularios, el texto se distribuye en una sola columna.

Otro detalle de enorme solemnidad es la ejecución de iniciales de mayor módulo y cuidado, y la utilización de colores como el rojo en los números de la foliación y sobre todo en los enormes incipit en portugués con el resumen del contenido de los documentos (algunos ocupan varias líneas), o el azul en los calderones que distribuían el contenido de los textos. Aunque comparándolo con otros códices de la Leitura Nova que además también emplean miniaturas iluminadas, resulta bastante austero ${ }^{13}$.

Un curioso detalle es una especie de mapa que aparece copiado en el folio $23 r$., en el que aparece delimitada la raya fronteriza en el entorno del concejo de

${ }^{10}$ M. C. ÁlVAREZ MARQUEZ, "Escritura latina en la Plena y Baja Edad Media, la llamada gótica libraria en España”, Historia, Instituciones, Documentos, 12 (1985), pp. 377-410 (http:// www.institucional.us.es/revistas/historia/12/12\%20alvarez\%20marquez.pdf).

${ }^{11}$ Proceso similar al de las escrituras cursivas que fue analizado por M. J. SANZ FUENTES, "La escritura gótica documental castellana”, en Paleografía II: Las escrituras góticas desde 1250 hasta la invención de la imprenta, Oviedo, 2010, pp. 107-126; y P. CUENCA MUÑOZ, "La escritura gótica cursiva castellana: su desarrollo histórico" en III Jornadas cientificas sobre documentación en la época de los Reyes Católicos, Madrid, 2004, pp. 23-34 (http://www.ucm.es/ data/cont/docs/446-2013-08-22-3\%20escritura.pdf).

${ }^{12}$ Este aspecto se conoce como "exactitud textual" y es un indicador de la calidad de la transcripción. L. MORELLE, "De l'original a la copie: remarques sur l'evaluation des transcriptions dans les cartularies médievaux", Les cartulaires, 1992, pp. 91-104.

${ }^{13}$ Los "espledorosos" frontispicios iluminados de otros códices de la Leitura Nova fueron estudiados y reproducidos en M. ALBURQUERQUE, Leitura Nova de Dom Manuel I, 2 vols., Lisboa, 1997. 
Olivenza, en la que se observa un territorio neutral que tiene diferentes longitudes medidas en la distancia de tiros de piedras o de ballesta.

Cuestión aparte a la que nos puede llevar el análisis físico del códice es la observación de diversos detalles disonantes dentro del cartulario. Un primer ejemplo es el índice de contenido que tiene todos los visos de haber sido realizado a posteriori, ya que a pesar de seguir las características generales de la ejecución del cartulario, podemos observar que se encuentra en un cuadernillo independiente, fuera de la paginación del códice, incluyendo el regesto de un documento que también fue incorporado a posteriori, escrito con una letra diferente y con una estructura a dos columnas que recuerda a los restantes cartularios de la Leitura Nova. Parece como si el códice fuera una pieza singular que no perteneciera inicialmente al mencionado fondo, pero que posteriormente fuese incluida y se intentó homogeneizarla con la inclusión de un índice y dos títulos con un formato similar al resto de la colección. El primero de ellos da nombre al códice y se encuentra antes del índice, dentro del nuevo cuadernillo independiente; mientras que el segundo inicia un nuevo apartado con el título "Contractos de pazes dentre Portugal e Castella" y se encuentra dentro del folio 112r. en el códice original, pero curiosamente ocupando el último folio del cuadernillo que se encuentra con anterioridad al primero que inicia el mencionado apartado, aprovechando un hueco que había quedado en blanco.

Pero no fue el único folio en blanco que se encontraba al final de ese cuadernillo que finaliza el apartado de disputas fronterizas. En los cuatro folios anteriores (108v.-111v.) aparece un documento con la ratificación portuguesa del acuerdo de Martim de Alburquerque con el rey de Calicut ${ }^{14}$ que poco tiene que ver con la temática y con la cronología del resto de los documentos, y que fue claramente añadido a posteriori ya que la letra empleada es diferente y además carece de la rúbrica de Fernão de Pina que aparece cerrando todos los restantes folios del códice.

Más adelante, dentro del segundo apartado correspondiente a los tratados de paz entre Castilla y Portugal, encontramos dos huecos en blanco de varios folios que separan los tres documentos. El primero de ellos de menor tamaño tiene su lógica en el intento por parte de la persona encargada de la ejecución del códice de que el siguiente tratado comenzará en un nuevo cuadernillo de pergamino. Mientras que el segundo es algo más enigmático ya que se encuentra en la parte central de un cuadernillo, pero no podemos determinar si es debido a un sobrante

\footnotetext{
${ }^{14}$ A.N.T.T., Leitura Nova, livro 61 (livro das pazes), 108v.-111v. [Doc. 53].
} 
en la previsión de espacio para el documento anterior, a que estaría reservado a otro documento que finalmente no fue redactado, o a que simplemente se quería dejar deliberadamente un espacio entre ambos documentos.

\section{ESTRUCTURA Y CONTENIDO DEL CÓDICE}

En el índice inicial del códice observamos que consta de 14 documentos, aunque esta cifra se aleja del número total ya que en la mayor parte de éstos se incluyen varios documentos insertos, por lo que la cifra real asciende a 53 documentos.

El códice se encuentra estructurado en dos grandes apartados. El primero de ellos carece de título, es el que mayor número de documentos contiene (11 documentos, 50 si tenemos en cuenta los insertos) y el que mayor extensión ocupa (111 folios de los 156 totales), su temática principal son los documentos sobre los arreglos de disputas fronterizas entre Castilla y Portugal, que aparecen sin seguir ningún orden cronológico o geográfico, y parece que son añadidos a medida que son hallados. Sin embargo, en su parte final aparecen dos documentos que poco tienen que ver con esa cuestión como son: una renovación por parte de Enrique IV de Inglaterra del tratado de amistad entre su reino y Portugal (el tratado de Windsor) de $1404^{15}$ y la mencionada ratificación de D. Manuel I de las paces acordadas entre su vasallo Alfonso de Alburquerque y el rey de Calicut de $1415^{16}$. A diferencia del tratado con el rey de Calicut, la renovación del tratado con los ingleses formaba parte del núcleo inicial del códice con las mismas características físicas e incluso se encuentra situado entre los documentos de disputas fronterizas ya que después de éste todavía se encuentra un contrato notarial sobre esas cuestiones.

Por el contrario el segundo apartado si tiene título específico: "Contratos de pazes dentre Portugal e Castela", dado su carácter circunscrito en los grandes tratados celebrados entre ambos reinos que aparecen en un orden cronológico decreciente: el tratado de Toledo de $1480^{17}$, el tratado de Medina del Campo de $1431^{18}$ y el Tratado de Alcañices de $1297^{19}$.

A pesar de que por el título del códice pueda parecer que su contenido sea bastante monotemático, tenemos una gran diversidad tipológica. Podemos dividir

\footnotetext{
${ }^{15}$ A.N.T.T., Leitura Nova, livro 61 (livro das pazes), 101v.-107v. [Doc. 32].

${ }^{16}$ A.N.T.T., Leitura Nova, livro 61 (livro das pazes), 108v.-111v. [Doc. 53].

17 A.N.T.T., Leitura Nova, livro 61 (livro das pazes), 113r.-140v. [Doc. 52].

18 A.N.T.T., Leitura Nova, livro 61 (livro das pazes), 142r.-165r. [Doc. 33].

${ }^{19}$ A.N.T.T., Leitura Nova, livro 61 (livro das pazes), 168r.-169v. [Doc. 5].
} 
los documentos en dos grandes grupos: los referentes a los tratados de paz y los concernientes a las disputas fronterizas.

En el primer grupo donde englobamos los tres tratados lusocastellanos y los dos tratados excéntricos, tenemos realmente nueve documentos de carácter notarial: una avenencia entre monarcas (el tratado de Alcañices de 1297), una avenencia entre las embajadas inglesa y portuguesa (el tratado de Windsor de 1386), cinco ratificaciones (ratificación del tratado de Windsor por Ricardo II de Inglaterra en 1387 y por Enrique IV en 1403; las ratificaciones castellanas de los tratados de Medina del Campo de 1431 y de Toledo de 1480, y la ratificación portuguesa al tratado con el rey de Calicut de 1515) y dos poderes (poderes a las delegaciones portuguesa e inglesa en el tratado de 1386) ${ }^{20}$.

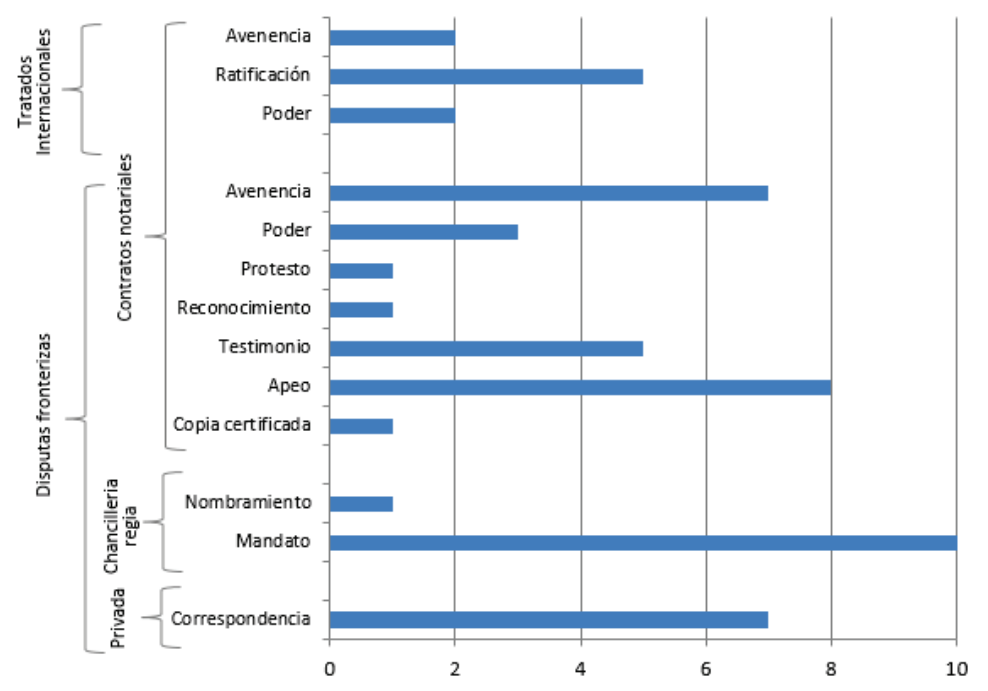

Imagen 1. Gráfica de las tipologías documentales del Livro das Pazes.

En el segundo grupo tenemos más si cabe una mayor riqueza tipológica que es reflejo de la complejidad política y jurídica que entrañaban las disputas fronterizas. La mayor parte corresponde a los 25 documentos notariales entre los que aparecen unas siete avenencias entre los encargados de negociarlas, tres poderes, un reconocimiento de delegación, cinco testimonios (tres de ausencia, uno de una entrevista y otro de no alcanzar un acuerdo), una protesta, ocho apeos (inquirições) y una copia certificada notarial de varios documentos de disputas fronterizas, de la que trataremos adelante ${ }^{21}$. También contiene 11 documentos de cancillería regia: un nombramiento de fronteiro y diez órdenes regias a sus delegados para

${ }^{20}$ Docs. 5, 30, 31, 32, 33, 52, 53, 28 у 29.

${ }^{21}$ Docs. 1, 2, 6, 14, 15, 36, 34 (avenencias); 7, 8, 35 (poderes); 9 (reconocimiento); 4, 10, 13, 19, 25 (testimonios); 3 (protesto); 17, 18, 20, 23, 24, 27, 43, 50 (apeos); y 51 (copia certificada notarial). 
resolver las disputas ${ }^{22}$. Finalmente aparecen 7 ejemplos de correspondencia entre las delegaciones fronterizas de sus reinos, que dadas sus intrínsecas características legales, pertenecen al grupo de documentación privada ${ }^{23}$.

Todos estos documentos procedían de los fondos del archivo de la monarquía portuguesa, el Arquivo da Torre do Tombo, por lo que en algunos casos disponemos del documento original en el mismo archivo en donde se custodia el propio cartulario, una cuestión conocida por los archivistas que señalaron a lápiz las signaturas de su correspondencia. Entre los que se perduran actualmente destacan los tratados internacionales, conservados en su integridad en el fondo Gavetas de la Torre do Tombo e incluso también en los fondos de otros archivos de monarquías europeas como el Archivo General de Simancas para el caso castellano o The National Archives para el caso inglés. También disponemos de documentos referentes a cuestiones de disputas fronterizas, en el mismo fondo de las Gavetas tenemos tres expediciones notariales que engloban un total de nueve documentos si tenemos en cuenta los insertos; pero en el fondo de chancillerías no hemos encontrado los correspondientes documentos regios.

Por lo general, los documentos originales que encontramos en el Archivo da Torre do Tombo se encuentran en buenas condiciones de conservación por lo que podemos desechar el argumento de que la intención principal del cartulario fuese la custodia de documentos que por aquel entonces se encontrasen en mal estado. Además cotejando el contenido de esos documentos originales, podemos indicar que las copias en el cartulario se realizaron con total fidelidad y que no hubo pretensión de reconstruir la memoria, algo que no es de extrañar porque la monarquía lusa era una institución en proceso de empoderamiento que no precisaba de manipular la memoria de unos documentos cuyo contenido además podía ser fácilmente comparado con el de los originales que estaban en manos de los castellanos ${ }^{24}$.

\section{EL CONTEXTO DE LA ELABORACIÓN DEL CÓDICE}

La pregunta más importante que nos atañe en el análisis del cartulario es tratar de conocer la intencionalidad de su elaboración, es decir, averiguar por qué las

\footnotetext{
${ }^{22}$ Docs. 11, 12, 16, 21, 22, 34, 38, 45, 48 y 49 (mandatos); y 37 (nombramiento).

${ }^{23}$ Docs. 26, 39, 40, 41, 42, 46 y 47.

${ }^{24}$ El objetivo del cartulario es meramente archivístico y no hay pretensión de reconstruir la memoria, como sucedió con las instituciones eclesiásticas que en la época plenomedieval utilizaron el cartulario como instrumento historiográfico que legitimase su subsistencia en un contexto de reforma administrativa. M. J. SANZ FUENTES, "Cartularios y falsificación histórica", en La memoria histórica de Cantabria, Santander, 1995, pp. 148-149.
} 
autoridades portuguesas consideraron conveniente hacer una recopilación de los documentos referentes a tratados y a disputas fronterizas con el vecino castellano, y copiarla en un libro solemne pero carente de una validación legal.

La preocupación de la monarquía lusa por la conservación de los documentos de este tipo de temáticas no parece ser una novedad, uno de los documentos del cartulario es la copia de un documento notarial en el que por orden de D. Afonso $\mathrm{V}$ de Portugal fueron copiados seis documentos referentes a las disputas fronterizas con el concejo de Olivenza, aunque en este caso se perseguía una intención de dotarle un valor legal al dotarle de la validación de un notario público e incluso realizar otra copia en papel destinada al archivo concejil ${ }^{25}$.

Si nos atenemos a las cuestiones de producción y validación, el precedente más inmediato a nuestro cartulario dentro del contexto portugués es un códice de 43 folios custodiado en el fondo Gavetas de la Torre do Tombo, que contiene una recopilación de doce documentos con tratados y acuerdos diplomáticos realizados entre Portugal e Inglaterra entre 1386 y $1436^{26}$.

Dadas las características formales del cartulario y los precedentes de recopilación de documentos con temáticas similares, podemos señalar que el livro das pazes tenía como fin la recopilación archivística de contratos de importancia capital en un formato que facilitaba su lectura y conservación ${ }^{27}$.

Sin embargo, su relación directa con los restantes códices del fondo de Leitura Nova no parece ser clara. Si aceptamos la datación en el siglo XVI de ese fondo, la primera duda que surge es la ausencia del tratado más importante: el tratado de Tordesillas de 1494. Por otra parte, muchas de las características formales del códice no coinciden con el formato de los restantes de la Leitura Nova, a pesar de que existan elementos añadidos posteriores como los títulos y el índice con la intención de homogeneizarlo.

Por ello deberíamos retrotraer la fecha de elaboración entre la data del último de los documentos que formaban parte del núcleo inicial, el tratado de Toledo de 1480, y esa emblemática fecha de 1494. E incluso podemos sugestionar que a pesar de ser considerado archivísticamente como el último de los libros de la Leitura Nova, podría ser el antecedente directo de esos cartularios ya que fue ela-

${ }^{25}$ A.N.T.T., Leitura Nova, livro 61 (livro das pazes), 1r.-40v. [Doc. 51], conservado su original en formato códice en A.N.T.T., Feitos da Coroa, Núcleo Antigo 31.

${ }^{26}$ A.N.T.T., Gavetas da Torre do Tombo, gaveta XVIII, maço 7, doc. 28. Editado en $A s$ Gavetas da Torre do Tombo, vol. IX, Lisboa, 1971, pp. 107-139 (4501).

${ }^{27}$ Cumple la función meramente archivística que se le atribuye a los cartularios en la época moderna, frente a la función jurídica de época medieval. C. MENDO CARMONA, "El cartulario como instrumento archivístico", Signo, 15 (2005), pp. 119-137 (http://hdl.handle.net/10017/7622). 
borado por Fernão de Pina, la persona a la que posteriormente se le encomendó la tarea de realizar los restantes cartularios en $1504^{28}$, tras haber sido uno de los integrantes de la misión de recopilar los forales del reino en $1497^{29}$. Finalmente alcanzó el cargo de guarda-moor de la Torre do Tombo en 1523, sucediendo en el cargo a su padre Rui de Pina, el famoso cronista ${ }^{30}$.

En la cronología señalada, sabemos que el joven Fernão de Pina se encontraba dentro de los núcleos de poder de las relaciones exteriores de la monarquía portuguesa. Por los textos cronísticos sabemos que actuó como secretario de una embajada a Inglaterra en 1482 para renovar el tratado de amistad originalmente acordado en Windsor en 1386 y para ampliarlo a las nuevas tierras descubiertas en Guinea $^{31}$, y que posteriormente fue nombrado secretario de una embajada en Flandes en 1488 para mediar entre Maximiliano, rey de romanos, y el Carlos VIII de Francia, que nunca se llevo a cabo porque Maximiliano fue apresado por los burgueses de Brujas en plena guerra civil en los Países Bajos borgoñones ${ }^{32}$. Posteriormente fue el encargado en 1498 de llevar las dudas de las Cortes de Lisboa al monarca D. Manuel I que se encontraba en Zaragoza jurando como heredero de los Reyes Católicos ${ }^{33}$.

La experiencia en asuntos con la monarquía ingleses de Fernão de Pina parece ser la causa más probable de que aparezca copiada dentro del códice la renovación en 1403 de los tratados de amistad entre Portugal e Inglaterra de Windsor en 1386, quien fácilmente pudiera tener contacto directo con el mencionado cartulario en donde se recopilaban los acuerdos con los ingleses. Mientras que la ratificación de D. Manuel I de los acuerdos con el rey de Calicut en 1515 parece ser una simple incorporación a posteriori que aprovecha los folios en blanco de un códice que le garantizaba su conservación.

Tenemos por tanto que el encargado de la redacción del cartulario, Fernão de Pina, era una persona que era muy consciente de la importancia de la conserva-

\footnotetext{
28 A.N.T.T., Gavetas da Torre do Tombo, gaveta XX, maço 10, docs. 6 y 7. Regestados en As Gavetas da Torre do Tombo, vol. XI, Lisboa, 1975, p. 18 (5635 y 5636).

${ }^{29}$ A.N.T.T., Corpo Chronológico, Parte I, maço 2, doc. 119.

${ }^{30}$ A.N.T.T., Chancelarias, Chancelaria de D. João III, livro 3, 36r.

${ }^{31}$ G. RESENDE, Chronica dos valerosos e insignes feitos del rey Dom Joam II de gloriosa memoria, Coimbra, 1798, p. 42 (cap. XXXIV); y J. C. SERRA, Collecção de livros ineditos de Historia Portuguesa dos reinados de D. João I, D. Duarte, D. Affonso V e D. João II, vol. II (Crónica de D. João II de Rui de Pina), Lisboa, 1792, pp. 25-26 (cap. VII). XXXII)

32 J. C. SERRA, Collecção..., vol. II (Crónica de D. João II de Rui de Pina), pp. 82-84 (cap.

${ }^{33}$ F. N. FRANKLIN, Memoria para servir de indice dos foraes das terras do reino de Portugal e seus dominios, Lisboa, 1816, p. II.
} 
ción y gestión de los documentos que garantizaban los derechos en las relaciones internacionales. Podríamos conjeturar que el cartulario pudiera ser elaborado expresamente como instrumento para gestionar una determinada actuación diplomática portuguesa, como podría ser la negociación del Tratado de Tordesillas de 1494, pero dada su condición de pieza solemne y carente de solemnidad, lo más probable es que fuese una pieza conservada en el archivo real construida para garantizar la memoria y facilitar la gestión de todas las actuaciones en las constantes e importantes relaciones luso-castellanas, siendo además dada su solemnidad, la plasmación material del empoderamiento de la monarquía lusa y de la génesis del estado moderno.

\section{CONCLUSIONES}

El "Livro das pazes" es la representación material de la preocupación de la monarquía portuguesa por conservar la memoria de los actos jurídicos más importantes que atañen a su reino, constituyendo las relaciones internacionales uno de sus pilares básicos, especialmente las mantenidas con sus vecinos castellanos, ya que la propia supervivencia del estado portugués dependía de mantener unas buenas relaciones y de delimitar claramente cuales eran los términos fronterizos. Además no parece ser un caso aislado en el contexto portugués en donde encontramos algunos precedentes inmediatos como un cartulario en el que se recopilaron los tratados de paz entre Portugal e Inglaterra desde 1386 y 1436.

Este códice custodiado en el fondo de Leitura Nova del Arquivo Nacional da Torre de Tombo no pertenecía inicialmente a la mencionada colección aunque es clave para su confección. Sabemos que fue elaborado por Fernão da Pina, encargado posteriormente de la elaboración de los códices de la Leitura Nova, pero la ausencia de documentos clave como el Tratado de Tordesillas, nos hace retrotraer su cronología a las dos décadas anteriores, pudiendo además considerarse como el precedente inmediato a esa gran obra de recopilación documental, a la que finalmente fue incorporado.

Se trata de una pieza elaborada con enorme solemnidad en un material lujoso como el pergamino, con una preparación y una escritura elaborada, y con algunos detalles que la embellecían como el uso de tintas de colores o la inclusión de iniciales decoradas.

En ella se contienen 53 documentos imprescindibles para el conocimiento de las relaciones luso-castellanas en la baja edad media, con una gran riqueza tipológica que va desde apeos de territorios fronterizos hasta grandes tratados inter- 
nacionales, e incluso de ámbitos diferentes como las relaciones con Inglaterra o con los soberanos de territorios en la India. Algunos de estos documentos son sobradamente conocidos como por ejemplo los mencionados tratados, pero otros han pasado desapercibidos por unos historiadores que apenas han considerado este cartulario como fuente para sus investigaciones, hecho que sin duda cambiará a partir de esta publicación.

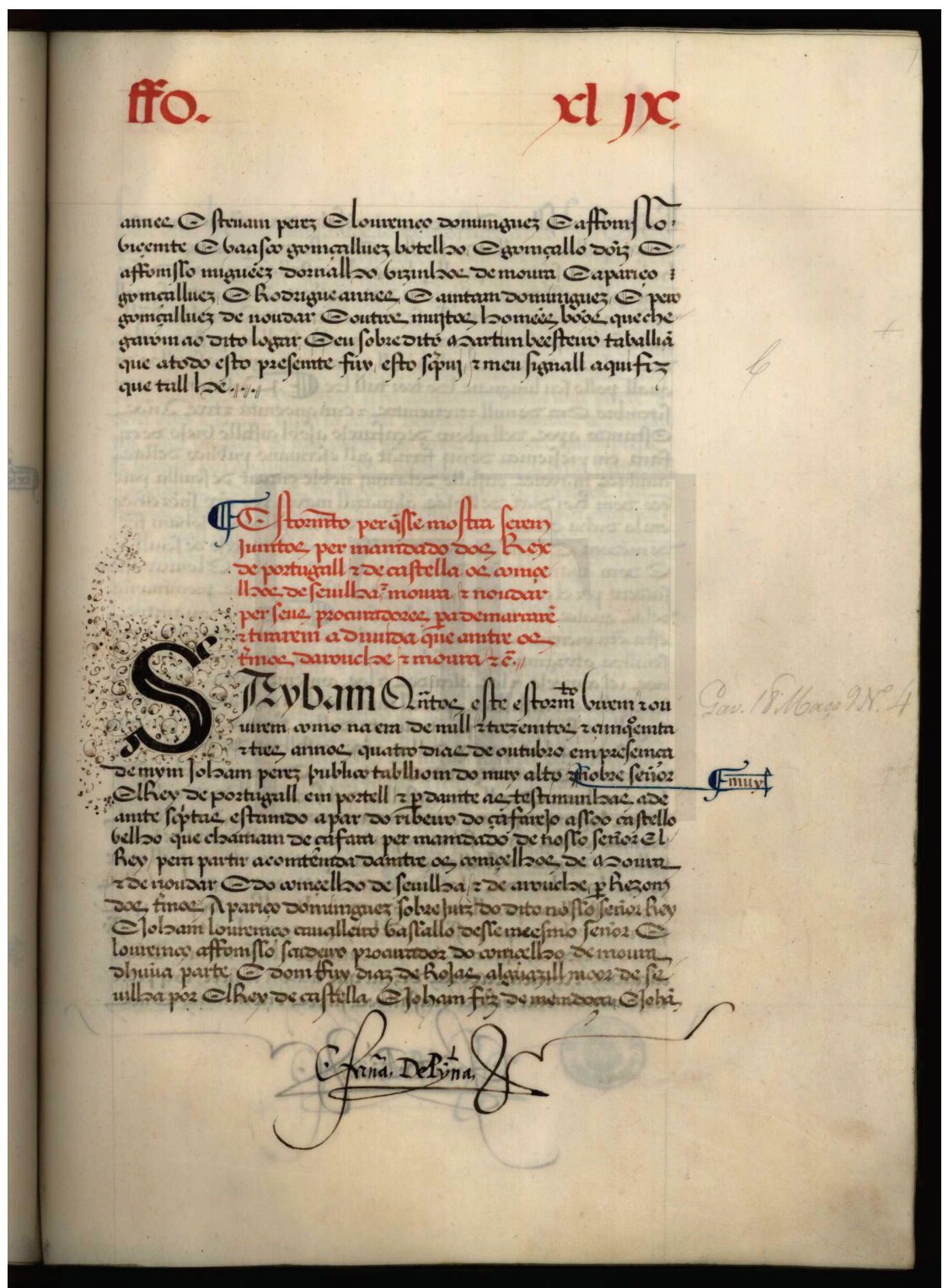

Imagen 2. Fotografía de uno de los folios del códice (49r.) en el que se puede apreciar diferentes detalles: escritura, pautado, márgenes, foliación, incipit con el resumen del documento, inicial decorada, marca a la lápiz de la signatura en las gavetas, corrección de palabra omitida en el margen lateral. 


\section{REGESTOS}

1287, octubre, 21. Sabugal-Sortelha.

Ruy Gómez, sobrejuez de D. Dinis I de Portugal, y Mateo de Benavente, alcalde de Sancho IV de Castilla, acuerdan realizar una partición entre Sortelha (Portugal) y Sabugal (Castilla), siendo las aguas del río Coa las que delimiten la frontera entre ambos reinos.

B.- Pergamino, folio, portugués.

A.N.T.T., Leitura Nova, livro 61 (livro das pazes), 43r.-44v.

1290, mayo, 20. Azinhal da Roda, Arronches.

Vasco Pérez, procurador de D. Dinis I de Portugal, y Juan de Rocha, procurador de Sancho IV de Castilla, acuerdan realizar una partición entre Arronchel (Portugal) y Badajoz (Castilla), para solucionar las disputas entre ambos municipios sobre un territorio fronterizo.

A.- Pergamino, portugués.

A.N.T.T., Gavetas da Torre do Tombo, gaveta XV, maço 23, documento 4 .

B.- Pergamino, folio, portugués.

A.N.T.T., Leitura Nova, livro 61 (livro das pazes), 40v.-43r.

Edt.: As gavetas da Torre do Tombo, vol. V, Lisboa, 1965, pp. 559-562 (3742).

\section{6, enero, 14. Aldea del Obispo.}

João (II), obispo de Lamego, protesta por la ausencia de los procuradores del rey de Castilla que debían de reunirse con los del rey de Portugal para realizar una partición de los territorios fronterizos entre los ríos Tajo y Duero.

B.- Pergamino, folio, portugués.

A.N.T.T., Leitura Nova, livro 61 (livro das pazes), 44v.-46r.

\section{4}

1296, enero, 20. Monforte de Río Libre.

Los procuradores de D. Dinis I de Portugal para delimitar los territorios fronterizos entre Castilla y Portugal entre los ríos Duero y Miño, levantan testimonio notarial de la ausencia de los procuradores de Fernando IV de Castilla.

B.- Pergamino, folio, portugués.

A.N.T.T., Leitura Nova, livro 61 (livro das pazes), 107v.-108v. 


\section{7, septiembre, 12. Alcañices.}

D. Dinis I de Portugal y Fernando IV de Castilla con la aquiescencia de la regente del reino, su madre María de Molina, firman un tratado (Tratado de Alcañices) en el que fijan las fronteras entre los reinos de Castilla y Portugal, solucionan disputas de circunscripciones religiosas fronterizas, y acuerdan el matrimonio de Fernando IV de Castilla con Constanza, hija de D. Dinis I de Portugal, $y$ de Afonso, príncipe heredero, con Beatriz, hermana de Fernando IV de Castilla.

A.- Pergamino (688 x $512 \mathrm{~mm})$, vestigios de cinco sellos pendientes, castellano.

A.N.T.T., Gavetas da Torre do Tombo, gaveta XVIII, maço 9, documento 13.

B.- Pergamino, folio, castellano.

A.N.T.T., Leitura Nova, livro 61 (livro das pazes), 168r.-169v.

B.- Pergamino, folio, castellano.

A.N.T.T., Leitura Nova, livro 39 (livro 2 dos reis), 139v.

Edt.: As gavetas da Torre do Tombo..., vol. IX, pp. 500-501 (4555).- M. GONZÁLEZ JIMÉNEZ, "Las relaciones entre Castilla y Portugal durante el siglo XIII", Revista da Faculdade de Letras da Universidade do Porto. História, 15 (1998) pp. 21-24.

\section{6}

\section{4, mayo, 13. São Veríssimo, Moura.}

João (I) Soares Alão, obispo de Silves, procurador de D. Dinis I de Portugal, acuerda con Ruy Pérez de Alcalá, alcalde mayor de Sevilla, procurador del concejo de Sevilla, que no haya ninguna actuación por parte de los concejos de Moura y Arronche hasta que no se solucionen las disputas fronterizas.

B.- Pergamino, portugués. Inserto en un documento notarial (doc. 10).

A.N.T.T., Gavetas da Torre do Tombo, gaveta XVIII, maço 9, documento 4.

C.- Pergamino, folio, portugués.

A.N.T.T., Leitura Nova, livro 61 (livro das pazes), 53r.-53v.

Edt.: As gavetas da Torre do Tombo..., vol. IX, p. 420 (4546).

\section{5, septiembre, 22. Sevilla.}

El concejo de Sevilla apodera a Ruy Díaz de Rojas, alguacil mayor de Sevilla, Juan Fernández Mendoza, Juan Ruiz de Fermosilla y Andrés de Monsalve, caballeros y vecinos de Sevilla, para realizar un acuerdo con los procuradores de D. Dinis I de Portugal para la partición los términos fronterizos de los concejos de Sevilla, Arronche (Castilla), Moura y Noudar (Portugal).

B.- Pergamino, traducido al portugués. Inserto en un documento notarial (doc. 9), a su vez inserto en otro (doc. 10).

A.N.T.T., Gavetas da Torre do Tombo, gaveta XVIII, maço 9, documento 4. 
C.- Pergamino, folio, traducido al portugués.

A.N.T.T., Leitura Nova, livro 61 (livro das pazes), 49v.-50r.

Edt.: As gavetas da Torre do Tombo..., vol. IX, pp. 415-416 (4546).

\section{8}

\section{5, septiembre, 28. Moura.}

El concejo de Moura apodera a Lourenço Afonso, escudero y vecino de Moura, para realizar un acuerdo con los procuradores de Alfonso XI de Castilla para la partición los términos fronterizos de los concejos de Sevilla, Arronche (Castilla), Moura y Noudar (Portugal).

B.- Pergamino, portugués. Inserto en un documento notarial Inserto en un documento notarial (doc. 9), as u vez inserto en otro (doc. 10).

A.N.T.T., Gavetas da Torre do Tombo, gaveta XVIII, maço 9, documento 4.

C.- Pergamino, folio, portugués.

A.N.T.T., Leitura Nova, livro 61 (livro das pazes), 50r.-51r.

Edt.: As gavetas da Torre do Tombo..., vol. IX, pp. 416-427 (4546).

\section{9}

\section{5, septiembre, 30. Arroyo de Zafareja.}

Ruy Díaz de Rojas, alguacil mayor de Sevilla, Juan Fernández Mendoza, Juan Ruiz de Fermosilla y Andrés de Monsalve, procuradores del concejo de Sevilla, reconocen a Aparicio Domínguez, sobrejuez de D. Dinis I de Portugal, João Lourenço y Airas Paez Bugalho, caballeros, y Lourenço Afonso, escudero, como procurador del concejo de Moura, para realizar un acuerdo de partición de los términos fronterizos de los concejos de Sevilla, Arronche (Castilla), Moura y Noudar (Portugal). Incluye inserto el contenido de los correspondientes poderes otorgados por el concejo de Sevilla con data 22 de septiembre de 1315 (doc. 7) y por el concejo de Moura con data 28 de septiembre de 1315 (doc. 8).

B.- Pergamino, castellano. Inserto en un documento notarial (doc. 10).

A.N.T.T., Gavetas da Torre do Tombo, gaveta XVIII, maço 9, documento 4.

C.- Pergamino, folio, portugués.

A.N.T.T., Leitura Nova, livro 61 (livro das pazes), 49v.-52r.

Edt.: As gavetas da Torre do Tombo..., vol. IX, pp. 415-418 (4546).

\section{0}

\section{5, octubre, 4-8. Arroyo de Zafareja.}

Aparicio Domínguez, sobrejuez de D. Dinis I de Portugal, Lourenço Afonso, escudero y procurador del concejo de Moura, levantan testimonio de cómo no llegan a un acuerdo con Ruy Díaz de Rojas, alguacil mayor de Sevilla, Juan Fernández Mendoza, Juan Ruiz de Fermosilla y Andrés de Monsalve, procuradores 
del concejo de Sevilla, para realizar un acuerdo de partición de los términos fronterizos de los concejos de Sevilla, Arronche (Castilla), Moura y Noudar (Portugal). Incluye inserto el contenido del reconocimiento de los emisarios portugueses datado en Arroyo de Zafareja el 30 de septiembre de 1315 (doc. 9) y de un acuerdo para evitar actuaciones hasta negociar datado en São Veríssimo, Moura, el 13 de mayor de 1304 (doc. 6).

A.- Pergamino, portugués.

A.N.T.T., Gavetas da Torre do Tombo, gaveta XVIII, maço 9, documento 4.

B.- Pergamino, folio, portugués.

A.N.T.T., Leitura Nova, livro 61 (livro das pazes), 49r.-54r.

Edt.: As gavetas da Torre do Tombo..., vol. IX, pp. 414-421 (4546).

\section{6, septiembre, 17. [Madrid] ${ }^{34}$.}

Alfonso XI de Castilla ordena a García Gómez, doctor, merino mayor en ciertas merindades de Galicia y alcalde del infante don Fadrique Alfonso de Castilla, maestre de Santiago, para recuperar las villas fronterizas de Hermisende y otras aldeas en terra de Seabra, que decidieron cambiar su fidelidad a Portugal, con la connivencia de D. Afonso VI de Portugal que se compromete a enviar a uno de sus caballeros para evitar una contienda.

B.- Pergamino, folio, traducido al portugués. Inserto en un documento notarial (doc. 14), a su vez inserto en otro (doc. 15).

A.N.T.T., Leitura Nova, livro 61 (livro das pazes), 62r.-62v.

\section{2}

\section{6, octubre, 4. Tentúgal.}

D. Afonso IV de Portugal ante la comunicación por parte de Alfonso XI de Castilla de que iba a enviar a Gómez Fernández y García Gómez, merinos, para recuperar las villas fronterizas de Hermisende y otras aldeas en terra de Seabra, que decidieron cambiar su fidelidad a Portugal, ordena a Pedro Estevez, corregidor en Tras-os-Montes, que supervise las actuaciones de los castellanos para evitar una contienda.

\footnotetext{
${ }^{34}$ El texto inserto del documento de la cancillería del sello de la poridad carece de data tópica, para reconstruirla nos valemos de los trabajo sobre la reconstrucción del itinerario del monarca castellano de F.P. CAÑAS GÁLVEZ, Itinerario de Alfonso XI de Castilla. Espacio, poder y corte (1325-1350), Madrid, 2014, pp. 424-426, M. C. LEÓN-SOTELO CASADO, y E. GONZÁLEZ CRESPO, "Notas para el itinerario de Alfonso IX en el periodo de 1344 a 1350", En la España Medieval, 5 (1986), pp. 582-583 (http://revistas.ucm.es/index.php/ELEM/article/ viewFile/ELEM8686120575A/24503).
} 
B.- Pergamino, folio, portugués. Inserto en un documento notarial (doc. 14), a su vez inserto en otro (doc. 15).

A.N.T.T., Leitura Nova, livro 61 (livro das pazes), 62v.-63v.

\section{6, octubre, 17. Hermisende.}

Pedro Estevez, corregidor en Tras-os-Montes, y Gonçalo Estevez, caballero, alcaide del castillo de Braganza, procuradores de D. Afonso IV de Portugal para resolver las disputas fronterizas sobre las villas de Hermisende y La Tejera que cambiaron a la soberanía portuguesa y son reclamadas por los castellanos, levantan testimonio notarial de la ausencia de los procuradores de Gómez Fernández y García Gómez, merinos, procuradores de Alfonso XI de Castilla.

B.- Pergamino, folio, portugués.

A.N.T.T., Leitura Nova, livro 61 (livro das pazes), 60v.-61v.

\section{4}

\section{6, octubre, 22. Hermisende.}

Pedro Estevez, corregidor en Tras-os-Montes, y Gonçalo Estevez, caballero, alcaide del castillo de Braganza, procuradores de D. Afonso IV de Portugal, acuerdan con García Gómez, doctor en decretos, merino y alcaide, procurador de Alfonso XI de Castilla, aplazar la solución de las disputas fronterizas sobre las villas de Hermisende, La Tejera, y la mitad de las aldeas de Castromil y Moimenta, que cambiaron a la soberanía portuguesa aprovechando la campaña de Alfonso XI contra los Benimerines (1340-1342), y son reclamadas por los castellanos, al próximo 1 de diciembre de 1346, para poder realizar una pesquisa cada una de las delegaciones y tomar una decisión. Incluye inserto el contenido de los correspondientes poderes otorgados por Alfonso XI de Castilla el 17 de septiembre de 1346 (doc. 11) y por D. Afonso IV de Portugal con data en Tentúgal el 4 de octubre de 1346 (doc. 12).

B.- Pergamino, folio, portugués. Inserto en un documento notarial (doc. 15).

A.N.T.T., Leitura Nova, livro 61 (livro das pazes), 61v.-67r.

\section{5}

\section{6, diciembre, 11-13. Braganza.}

Pedro Estevez, corregidor en Tras-os-Montes, procurador de D. Afonso IV de Portugal, acuerda con García Gómez, doctor, morador en Salamanca, procurador de Alfonso XI de Castilla, aplazar la solución a las disputas fronterizas sobre las villas de Hermisende y La Tejera que cambiaron a la soberanía portuguesa y son reclamadas por los castellanos, al próximo 21 de junio de 1347, para 
así poder informar a sus respectivos monarcas de los resultados de las pesquisas realizadas por cada una de las delegaciones, y la contienda existente entre concejo de Braganza (Reino de Portugal), y el concejo de Puebla de Sanabria (Reino de Castilla) y el comendador de Castrotorafe, para así tomar una decisión. Incluye inserto el contenido del acuerdo de aplazamiento de las negociaciones datado en Hermisende el 22 de octubre de 1346 (doc. 14).

B.- Pergamino, folio, portugués.

A.N.T.T., Leitura Nova, livro 61 (livro das pazes), 61v.-67r.

\section{6}

\section{7, junio, 10. Santarém.}

D. Afonso IV de Portugal ordena a Pedro Estevez, corregidor en Tras-osMontes, que tome las medidas que sean necesarias para solucionar las disputas fronterizas sobre las villas de Hermisende y La Tejera que cambiaron a la soberanía portuguesa y son reclamadas por los castellanos, y solucionar el conflicto existente entre el concejo de Braganza, y Alfonso XI de Castilla, el infante Fadrique Alfonso de Castilla, conde de Trastámara y maestre de Santiago, y el concejo de Puebla de Sanabria.

B.- Pergamino, folio, portugués. Inserto en un documento notarial (doc. 17).

A.N.T.T., Leitura Nova, livro 61 (livro das pazes), 72v.-73r.

\section{7}

\section{7, junio, 23 - julio, 7. Braganza.}

Pedro Estevez, que fue corregidor en Tras-os-Montes, procurador de D. Afonso IV de Portugal, realiza un apeo (inquirição) a João Estevez, juez regio en Braganza, Afonso Roiz, procurador del concejo de Braganza, Antonio Martínez y Vicente Domínguez, vereadores, Pedro de Alcamças, Domingo Crespo, Vasco Pérez y Diego Domínguez, mercaderes, Ruy López, notario, y Nuno Fernández, escribano del rey; para determinar cuáles son los derechos de Portugal en las disputas fronterizas sobre las villas de Hermisende y La Tejera que cambiaron a la soberanía portuguesa y son reclamadas por los castellanos. Incluye inserto el contenido de la orden dada por D. Afonso IV de Portugal con data en Santarém el 10 de junio de 1347 (doc. 16).

B.- Pergamino, folio, portugués.

A.N.T.T., Leitura Nova, livro 61 (livro das pazes), 72v.-80v. 


\section{7, julio, 16. Hermisende.}

Pedro Estevez, que fue corregidor en Tras-os-Montes, morador en Portalegre, procurador de D. Afonso IV de Portugal, realiza un apeo (inquirição) a João Coelho, corregidor en Tras-os-Montes, Vasco Pérez, oidor en su lugar, Gonçalo Estevez, caballero y alcaide de Braganza, João Estevez, juez regio en Braganza, Martín Méndez, Álvaro Roiz, vasallo del rey y morador en Braganza, y Ruy Martínez, canciller del rey en Tras-os-Montes; para determinar cuáles son los derechos de Portugal en las disputas fronterizas sobre las villas de Hermisende y La Tejera que cambiaron a la soberanía portuguesa y son reclamadas por los castellanos.

B.- Pergamino, folio, portugués.

A.N.T.T., Leitura Nova, livro 61 (livro das pazes), 80v.-83r.

\section{7, julio, 16. Hermisende.}

Pedro Estevez, corregidor en Tras-os-Montes, y Gonçalo Estevez, caballero, alcaide del castillo de Braganza, procuradores de D. Afonso IV de Portugal, levantan testimonio de la entrevista que tuvieron con García Gómez, doctor en decretos, alcaide y merino mayor en Galicia, procurador de Alfonso XI de Castilla, para solucionar las disputas fronterizas sobre las villas de Hermisende, La Tejera, y la mitad de las aldeas de Castromil y Moimenta, que cambiaron a la soberanía portuguesa y son reclamadas por los castellanos.

B.- Pergamino, folio, portugués.

A.N.T.T., Leitura Nova, livro 61 (livro das pazes), 83r.-86r.

\section{7, octubre, 15. Alconchel.}

Gómez Anes, juez de Olivenza, Afonso Anes, procurador del concejo de Olivenza, Fernán Domínguez, vicario de Olivenza, Gonçalo Anes, notario en Olivenza, y Fernán Pérez, su escribano, junto con Alfonso Pérez, procurador del concejo de Alconchel, Alfonso Anes y Bartolomeu Filho, alcaide de Alconchel, realizaron un apeo (inquirição) para solucionar las disputas fronterizas en los términos de Olivenza (Portugal) y Alcochel (Castilla).

B.- Pergamino, folio, portugués. Inserto en un documento notarial (doc. 27).

A.N.T.T., Gavetas da Torre do Tombo, gaveta XV, maço 24, documento 13, 11v.-13v.

C.- Pergamino, folio, portugués. Inserto en un documento notarial (doc. 27) que a su vez está inserto en otro documento notarial (doc. 51).

A.N.T.T., Leitura Nova, livro 61 (livro das pazes), 11r.-12v. 
Edt.: As gavetas da Torre do Tombo..., vol. V, pp. 700-702 (4453).

\section{3, febrero, 12. Évora.}

D. Afonso IV de Portugal ordena a los concejos de la comarca de Moura que nombren procuradores para reunirse con Gómez Airas de Arca, alcalde mayor de Sevilla, y Juan Fernández, alcalde que fue en Sevilla, procuradores del concejo de Sevilla, para solucionar las disputas fronterizas con los términos de Arronches (Castilla).

B.- Pergamino, portugués. Inserto en un documento notarial (doc. 25).

A.N.T.T., Gavetas da Torre do Tombo, gaveta XVIII, maço 5, documento 31

B.- Pergamino, folio, portugués.

A.N.T.T., Leitura Nova, livro 61 (livro das pazes), 47r.-47v.

Edt.: As gavetas da Torre do Tombo, vol. VIII, Lisboa, 1970, pp. 564-565 (4453).

\section{2}

\section{3, febrero, 13. Évora.}

D. Afonso IV de Portugal, acepta la propuesta castellana de realizar un apeo (inquirição) conjunto con obispo de Badajoz, Lorenzo Gonçalves de Pedroso, y Suero Fernández Chanca, procuradores de Pedro I de Castilla, para solucionar las disputas fronterizas entre los términos de Olivenza (Portugal) y los de Badajoz, Figueira y Alcochel (Castilla), ordenando enviar a sus propios procuradores para llevarlo a cabo.

B.- Pergamino, folio, portugués. Inserto en un documento notarial (doc. 27).

A.N.T.T., Gavetas da Torre do Tombo, gaveta XV, maço 24, documento 13, 2v.-3r.

C.- Pergamino, folio, portugués. Inserto en un documento notarial (doc. 27) que a su vez está inserto en otro documento notarial (doc. 51).

A.N.T.T., Leitura Nova, livro 61 (livro das pazes), 2r.-2v.

Edt.: As gavetas da Torre do Tombo..., vol. V, pp. 688-689 (4453).

\section{3}

\section{3, febrero, 20. Braganza.}

Investigación (inquirição) a varios moradores de las villas de Braganza, Hermisende, Puebla de Sanabria, Moimenta, Castromil, y otras villas fronterizas entre Castilla y Portugal para determinar cuales son los derechos de Portugal en las disputas fronterizas sobre las villas de Hermisende y La Tejera que cambiaron a la soberanía portuguesa y son reclamadas por los castellanos.

B.- Pergamino, folio, portugués.

A.N.T.T., Leitura Nova, livro 61 (livro das pazes), 86r.-101r. 


\section{3, marzo, 1. Campo Maior.}

Pedro Martínez Alcoforado y Martín Gómez, caballeros, y Stevam Martínez Pegado, procuradores de D. Afonso IV de Portugal, realizan un apeo (inquirição) a los vecinos de Campo Maior (Portugal) para determinar cuáles son los términos fronterizos con los del concejo de Badajoz (Castilla).

B.- Pergamino, folio, portugués.

A.N.T.T., Leitura Nova, livro 61 (livro das pazes), 54r.-60r.

\section{5}

\section{3, marzo, 1-5. São Veríssimo, Moura.}

João Gómez, clérigo del rey y canónigo de Évora, y Stevam Lourenço, procuradores de D. Afonso IV de Portugal, levantan testimonio levantan testimonio notarial de la ausencia de Gómez Airas de Arca, alcalde mayor de Sevilla, y Juan Fernández, alcalde que fue en Sevilla, procuradores del concejo de Sevilla, para solucionar las disputas fronterizas en los términos de Arronches (Castilla) y Moura (Portugal). Incluye inserto el contenido de la orden de D. Afonso IV a los concejos de la comarca de Moura para nombrar procuradores datado en Évora el 12 de febrero de 1353 (doc. 21).

A.- Pergamino, portugués.

A.N.T.T., Gavetas da Torre do Tombo, gaveta XVIII, maço 5, documento 31.

B.- Pergamino, folio, portugués.

A.N.T.T., Leitura Nova, livro 61 (livro das pazes), 46r.-49r.

Edt.: As gavetas da Torre do Tombo..., vol. VIII, pp. 562-566 (4453).

\section{6}

1353, [febrero, 13 - marzo, 8].

Gonzalo Fernández Chanca, procurador de Pedro I de Castilla, comunica a Pedro Martínez Alcoforado, Martín Gómez, Stevam Martínez Pegado y Gonçalo Fernández Chanca, procuradores de D. Afonso IV de Portugal, que ha recibido su propuesta de encontrarse el próximo 8 de marzo de 1353 para solucionar las disputas fronterizas entre los términos de Olivenza (Portugal) y los de Badajoz, Figueira y Alcochel (Castilla), pero que no acudirá porque no se lo ha ordenado su monarca.

B.- Pergamino, folio, portugués. Inserto en un documento notarial (doc. 27).

A.N.T.T., Gavetas da Torre do Tombo, gaveta XV, maço 24, documento 13, 3r.

C.- Pergamino, folio, portugués. Inserto en un documento notarial (doc. 27) que a su vez está inserto en otro documento notarial (doc. 51).

A.N.T.T., Leitura Nova, livro 61 (livro das pazes), 3r.-3v. 
Edt.: As gavetas da Torre do Tombo..., vol. V, p. 690 (4453).

\section{3, marzo, 9. Olivenza.}

Pedro Martínez Alcoforado, Martín Gómez, y Stevam Martínez Pegado, procuradores de D. Afonso IV de Portugal, realizan un apeo (inquirição) para solucionar las disputas fronterizas entre los términos de Olivenza (Portugal) y los de Badajoz, Figueira y Alcochel (Castilla). Incluye inserto el contenido de la orden dada por Alfonso IV de Portugal, datada en Évora el 13 de febrero de 1353 (doc. 22), de la comunicación de ausencia por parte de los procuradores castellanos, datada entre febrero y marzo de 1353 (doc. 26), y de otra investigación conjunta entre castellanos y portugueses realizada años atrás, datada en Alconchel el 15 de octubre de 1347 (doc. 20).

B.- Pergamino, folio, portugués.

A.N.T.T., Gavetas da Torre do Tombo, gaveta XV, maço 24, documento 13, 1v.-13v.

C.- Pergamino, folio, portugués. Inserto en un documento notarial (doc. 51).

A.N.T.T., Leitura Nova, livro 61 (livro das pazes), 1v.-12v.

Edt.: As gavetas da Torre do Tombo..., vol. V, pp. 688-689 (4453).

\section{8}

\section{5, abril, 15. Coímbra.}

João I apodera a Fernando Afonso de Albuquerque, maestre de Santiago, e Lourenço João Fogaça, canciller del reino, para negociar el tratado de paz y amistad con Ricardo II de Inglaterra.

A.- Pergamino, folio, latín.

The National Archives (T.N.A.), E30 - Records of the treasury of receipt, Exchequer: diplomatic documents, documento 307.

B.- Papel, folio, latín.

T.N.A., C47 - Chancery Miscellanea, 30 - Diplomatic Documents, documentos 8/19 y 8/20

C.- Pergamino, folio, latín. Inserto en documento notarial (doc. 30).

T.N.A., E30 - Records of the treasury of receipt, Exchequer: diplomatic documents, documento 310 .

D.- Pergamino $(500 \times 760 \mathrm{~mm})$, latín. Inserto en documento notarial (doc. 30), a su vez inserto en otro (doc. 31).

A.N.T.T., Gavetas da Torre do Tombo, gaveta XVIII, maço 3, documento 25.

E.- Papel, folio, traducido al portugués. Inserto en documento notarial (doc. 30), a su vez inserto en otro (doc. 31).

A.N.T.T., Corpo Cronológico, Parte I, maço 1, documento 10, 5r-6r.

F.- Pergamino, latín. Inserto en documento notarial (doc. 30), a su vez inserto en otro (doc. 31) y éste a su vez inserto en otro (doc. 32).

A.N.T.T., Gavetas da Torre do Tombo, gaveta XVII, maço 2, documento 7. 
G.- Pergamino, folio, latín. Inserto en documento notarial (doc. 30), a su vez inserto en otro (doc. 31) y éste a su vez inserto en otro (doc. 32).

A.N.T.T., Gavetas da Torre do Tombo, gaveta XVIII, maço 7, documento 28, 16r.-17v.

H.- Pergamino, folio, latín. Inserto en documento notarial (doc. 30), a su vez inserto en otro (doc. 31) y éste a su vez inserto en otro (doc. 32).

A.N.T.T., Leitura Nova, livro 61 (livro das pazes), 105r.-106r.

Edt.: SILVA, José Soares da, Collecçam dos documentos com que se authorizam as memorias para a vida del Rey D. João I, vol. IV, Lisboa, 1734, pp. 237-240 (32), 257-260 (34).RYMER, Thomas, Foedera, conventiones, literae, et cuiscumque generis acta publica, inter reges angliae et alios quosvis imperatores, reges, pontifices, principes, vel communitares ab saeculo duodecimo, viz ab anno 1101, vol. VII, London, 1739-1745, pp. 518-519.- As gavetas da Torre do Tombo, VI, Lisboa, 1967, pp. 608-610 (4101), VIII, pp. 317-319 (4386), y IX, pp. 123-124 (4501).

\section{9}

\section{6, abril, 12. Westminster.}

Ricardo II de Inglaterra apodera a Richard of Alberbury, John Clanowe e Richard of Ronhale, doctor en leyes, para negociar el tratado de paz y amistad con João I de Portugal.

B.- Pergamino, folio, latín. Inserto en documento notarial (doc. 30).

T.N.A., E30 - Records of the treasury of receipt, Exchequer: diplomatic documents, documento 310 .

C.- Pergamino (500X760mm), latín. Inserto en documento notarial (doc. 30), a su vez inserto en otro (doc. 31).

A.N.T.T., Gavetas da Torre do Tombo, gaveta XVIII, maço 3, documento 25.

D.- Papel, folio, traducido al portugués. Inserto en documento notarial (doc. 30), a su vez inserto en otro (doc. 31).

A.N.T.T., Corpo Cronológico, Parte I, maço 1, documento 10, 4v-5r.

E.- Pergamino, latín. Inserto en documento notarial (doc. 30), a su vez inserto en otro (doc. 31) y éste a su vez inserto en otro (doc. 32).

A.N.T.T., Gavetas da Torre do Tombo, gaveta XVII, maço 2, documento 7.

F.- Pergamino, folio, latín. Inserto en documento notarial (doc. 30), a su vez inserto en otro (doc. 31) y éste a su vez inserto en otro (doc. 32).

A.N.T.T., Gavetas da Torre do Tombo, gaveta XVIII, maço 7, documento 28, 15r.-16r.

G.- Pergamino, folio, latín. Inserto en documento notarial (doc. 30), a su vez inserto en otro (doc. 31) y éste a su vez inserto en otro (doc. 32).

A.N.T.T., Leitura Nova, livro 61 (livro das pazes), 104r.-105r.

Edt.: SILVA, José Soares da, Collecçam dos documentos com que se authorizam..., vol. IV, pp. 235-237 (32), 255-257 (34).- RYMER, Thomas, Foedera..., vol. VII, pp. 519-520.- As gavetas da Torre do Tombo..., VI, pp. 607-608 (4101), VIII, pp. 316-317 (4386), y IX, pp. 122-123 (4501). 
1386, mayo, 9. Windsor.

Richard of Alberbury, John Clanowe e Richard of Ronhale, doctor en leyes, procuradores de Ricardo II de Inglaterra, acuerdan con Fernando Afonso de Albuquerque, maestre de Santiago, e Lourenço João Fogaça, canciller del reino, procuradores de João I de Portugal, un tratado de paz y amistad entre sus reinos, el conocido como Tratado de Windsor. Incluye inserto los correspondientes poderes a los embajadores otorgados por João I con data de Coímbra 15 de abril de 1385 (doc. 28) y por Ricardo II con data Westminster 12 de abril de 1385 (doc. 29).

A.- Pergamino, folio, latín.

T.N.A., E30 - Records of the treasury of receipt, Exchequer: diplomatic documents, documento 310 .

B.- Pergamino (500X760mm), latín. Inserto en documento notarial (doc. 31).

A.N.T.T., Gavetas da Torre do Tombo, gaveta XVIII, maço 3, documento 25.

C.- Papel, folio, traducido al portugués. Inserto en documento notarial (doc. 31).

A.N.T.T., Corpo Cronológico, Parte I, maço 1, documento 10, 1r.-6r.

D.- Pergamino, latín. Inserto en documento notarial (doc. 31), a su vez inserto en otro (doc. 32).

A.N.T.T., Gavetas da Torre do Tombo, gaveta XVII, maço 2, documento 7.

E.- Pergamino, folio, latín. Inserto en documento notarial (doc. 31), a su vez inserto en otro (doc. 32).

A.N.T.T., Gavetas da Torre do Tombo, gaveta XVIII, maço 7, documento 28, 9v.-18r.

F.- Pergamino, folio, latín. Inserto en documento notarial (doc. 31), a su vez inserto en otro (doc. 32).

A.N.T.T., Leitura Nova, livro 61 (livro das pazes), 101v.-106r.

Edt.: SILVA, José Soares da, Collecçam do documentos com que se authorizam..., vol. IV, pp. 226-240 (32), 246-260 (34).- RYMER, Thomas, Foedera..., vol. VII, pp. 515-521.- As gavetas da Torre do Tombo..., VI, pp. 603-610 (4101), VIII, pp. 312-319 (4386), y IX, pp. 117-124 (4501).

\section{7, febrero, 24. Westminster.}

Ricardo II de Inglaterra ratifica el tratado de paz y amistad con João I de Portugal que negociaron sus procuradores Richard of Alberbury, John Clanowe e Richard of Ronhale, doctor en leyes, procuradores de Ricardo II de Inglaterra, con Fernando Afonso de Albuquerque, maestre de Santiago, e Lourenço João Fogaça, canciller del reino, procuradores de João I de Portugal. Incluye inserto el contenido del acuerdo datado en Windsor el 9 de mayo de 1386 (doc. 30).

A.- Pergamino (500X760mm), latín. 
A.N.T.T., Gavetas da Torre do Tombo, gaveta XVIII, maço 3, documento 25.

B.- Papel, folio, traducido al portugués.

A.N.T.T., Corpo Cronológico, Parte I, maço 1, documento 10, 1r.-7v.

C.- Pergamino, latín. Inserto en documento notarial (doc. 32).

A.N.T.T., Gavetas da Torre do Tombo, gaveta XVII, maço 2, documento 7.

D.- Pergamino, folio, latín. Inserto en documento notarial (doc. 24/2/1387) que a su vez está inserto en otro documento notarial Inserto en documento notarial (doc. 32).

A.N.T.T., Gavetas da Torre do Tombo, gaveta XVIII, maço 7, documento 28, 9v.-19v.

E.- Pergamino, folio, latín. Inserto en documento notarial (doc. 24/2/1387) que a su vez está inserto en otro documento notarial Inserto en documento notarial (doc. 32).

A.N.T.T., Leitura Nova, livro 61 (livro das pazes), 101v.-106v.

Edt.: SILVA, José Soares da, Collecçam dos documentos..., vol. IV, pp. 226-243 (32), 246263 (34).- As gavetas da Torre do Tombo..., VI, pp. 603-611 (4101), VIII, pp. 312-320 (4386), y IX, pp. 117-126 (4501).

\section{4, febrero, 16. Westminster.}

Enrique IV de Inglaterra ratifica el tratado de paz y amistad con D. João I de Portugal que fue acordado y ratificado por su padre Ricardo II de Inglaterra. Incluye inserto el contenido de la ratificación datada en Westminster el 24 de febrero de 1387 (doc. 31).

A.- Pergamino, latín.

A.N.T.T., Gavetas da Torre do Tombo, gaveta XVII, maço 2, documento 7.

B.- Pergamino, folio, latín.

A.N.T.T., Gavetas da Torre do Tombo, gaveta XVIII, maço 7, documento 28, 9v.-20v.

C.- Pergamino, folio, latín.

A.N.T.T., Leitura Nova, livro 61 (livro das pazes), 101v.-107v.

R.- Papel, folio, latín.

T.N.A., C76 - Chancery: Treaty Rolls (French Rolls), 1404 ( $5^{\text {th }}$ year of the reign of Henry IV), m. 9.

Edt.: SILVA, José Soares da, Collecçam dos documentos com que se authorizam..., vol. IV, pp. 246-266 (34).- RYMER, Thomas, Foedera..., vol. VIII, p. 347.- As gavetas da Torre do Tombo.., VI, pp. 603-612 (4101) [Error al datarlo en 1403], IX, pp. 117-127 (4501).

1431, octubre, 30. Medina del Campo.

Juan II de Castilla ratifica las paces acordadas con D. João I de Portugal poniendo fin a las disputas entre ambos reinos desde la fallida proclamación de Juan I como rey de Portugal (1383).

B.- Pergamino, folio, castellano. Inserto parcial en documento notarial.

Archivo General de Simancas (A.G.S.), Patronato Real, Legajo 49, doc. 44, 193v.-200v.

B.- Pergamino, folio, castellano. Inserto parcial en documento notarial. 
A.G.S., Patronato Real, Legajo 49, doc. 53, 317v.-323r.

C.- Pergamino, folio, castellano. Inserto parcial en documento notarial.

A.N.T.T., Gavetas da Torre do Tombo, gaveta XVII, maço 6, documento 16, 3v.-12v.

D.- Pergamino, folio, castellano.

A.N.T.T., Leitura Nova, livro 61 (livro das pazes), 142r.-165r.

Edt.: Monumenta Henricina, vol. IV, Coímbra, 1962, pp. 18-53 (9) [Versión completa del livro das pazes].- J. S. SILVA, Collecçam do documentos com que se authorizam...I, vol. IV, pp. 270-358 (36).- F. GARDINER DAVENPORT, European Treaties bearing on the history of the United States and its dependencies, vol. I, Washington, 1917, pp. 33-48.- J. LÓPEZ DE TORO, Tratados internacionales de los Reyes Católicos, vol. IV, Madrid, 1952, pp. 125-128 [Edición basada en BNE, ms. 1890 y 2420].- As gavetas da Torre do Tombo..., vol. IX, pp. 500-501 (4555).- A. TORRE y L. SUÁREZ FERNÁNDEZ, Documentos referentes a las relaciones con Portugal durante el reinado de los Reyes Católicos, vol. I, Valladolid, 1958, pp. 253-273 (165).L. A. FONSECA y J. M. RUIZ ASENCIO, Corpus documental del Tratado de Tordesillas, Valladolid, 1995, pp. 68 (29).

1435, marzo, 23. Évora.

D. Duarte I de Portugal, acepta la propuesta castellana de encontrarse con los procuradores del concejo de Badajoz para solucionar las disputas fronterizas entre Barcarrota (Castilla) y Olivenza (Portugal), ordenando enviar a sus propios procuradores para llevarla a cabo.

B.- Pergamino, folio, portugués. Inserto en un documento notarial (doc. 36) que a su vez está inserto en otro documento notarial (doc. 51).

A.N.T.T., Leitura Nova, livro 61 (livro das pazes), 14r.-14v.

\section{5, abril, 2. Badajoz.}

El concejo de Badajoz apodera a Gonzalo Anes y Ruy Benitez, regidores de Badajoz, y a Juan Ruiz de Almazom, bachiller en leyes, vecinos de Badajoz, para que ellos junto a Diego Martínez, alcaide de Badajoz, acudan junto a los procuradores de D. Duarte I de Portugal, para solucionar las disputas fronterizas entre Barcarrota (Castilla) y Olivenza (Portugal).

B.- Pergamino, folio, traducido al portugués. Inserto en un documento notarial (doc. 36) que a su vez está inserto en otro documento notarial (doc. 51).

A.N.T.T., Leitura Nova, livro 61 (livro das pazes), 13r.-14r. 


\section{6}

$1435^{35}$, abril, 6. [Barcarrota - Olivenza].

Diego Martínez das Garrovilhas, alcaide de Badajoz y bachiller en leyes, por Juan Ruiz de Fonseca, guarda mayor y juez de Juan II de Castilla en Badajoz, junto con Ruy Benitez, regidor de Badajoz, y a Juan Ruiz de Almazom, bachiller en leyes, procuradores de Badajoz, acuerdan con Rodríguez, juez de D. Duarte I en Évora, y Lourenço Afonso y João Vazmeira, el mozo, juezes en Olivenza, junto con Garçía Ruiz Lobo y otros procuradores de Olivenza, solucionar las disputas fronterizas entre Barcarrota (Castilla) y Olivenza (Portugal), a través de un apeo (inquirição) conjunto. Incluye inserto el contenido de los correspondientes poderes otorgados por D. Duarte I de Portugal con data en Évora el 23 de marzo de 1435 (doc. 34) y por el concejo de Badajoz con data el 2 de abril de 1435 (doc. 35).

B.- Pergamino, folio, portugués. Inserto en un documento notarial (doc. 51).

A.N.T.T., Leitura Nova, livro 61 (livro das pazes), 12v.-20r.

\section{9, abril, 15. Santarém.}

D. Afonso $V$ de Portugal nombra como fronteiro de la comarca de Olivenza a Martim Afonso de Melo, del consejo, guarda mayor y alcaide de Olivenza.

B.- Pergamino, folio, portugués. Inserto en un documento notarial (doc. 51).

A.N.T.T., Leitura Nova, livro 61 (livro das pazes), 35r.

1454, marzo, 30. Viseu.

D. Afonso V de Portugal ordena a Martim Vicente de Villalobos, caballero, corregidor en la comarca entre los ríos Tajo y Guadiana, realizar un apeo (inquirição), para solucionar las disputas fronterizas de Olivenza (Portugal) con Barcarrota, Figueira y Alconchel (Portugal).

B.- Pergamino, folio, portugués. Inserto en un documento notarial (doc. 43) que a su vez está inserto en otro documento notarial (doc. 51).

A.N.T.T., Leitura Nova, livro 61 (livro das pazes), 20v.-21r.

35 En la data crónica de la transcripción en el Livro das pazes aparece como expedido en 1445 , pero se trata claremente de un error del copista ya que los hechos, los personajes implicados y los documentos insertos corresponden a 1435. 
1454, julio, 16. Olivenza.

Martim Vicente de Villalobos, caballero, corregidor en la comarca entre los ríos Tajo y Guadiana, comunica al concejo castellano de Barcarrota que va a realizar un apeo (inquirição) por orden de D. Afonso V de Portugal para solucionar las disputas fronterizas con Olivenza (Portugal).

B.- Pergamino, folio, portugués. Inserto en un documento notarial (doc. 43) que a su vez está inserto en otro documento notarial (doc. 51).

A.N.T.T., Leitura Nova, livro 61 (livro das pazes), 21r.

\section{0}

\section{4, julio, 17. Barcarrota.}

El concejo de Barcarrota responde favorablemente a Martim Vicente de Villalobos, caballero, corregidor en la comarca entre los rios Tajo y Guadiana, para la realización un apeo (inquirição) por orden de D. Afonso V de Portugal para solucionar las disputas fronterizas con Olivenza (Portugal).

B.- Pergamino, folio, portugués. Inserto en un documento notarial (doc. 43) que a su vez está inserto en otro documento notarial (doc. 51).

A.N.T.T., Leitura Nova, livro 61 (livro das pazes), 21r.-21v.

\section{1}

\section{4, julio, 18. Olivenza.}

Martim Vicente de Villalobos, caballero, corregidor en la comarca entre los ríos Tajo y Guadiana, comunica al concejo castellano de Figueira que va a realizar un apeo (inquirição) por orden de D. Afonso $V$ de Portugal para solucionar las disputas fronterizas con Olivenza (Portugal).

B.- Pergamino, folio, portugués. Inserto en un documento notarial (doc. 43) que a su vez está inserto en otro documento notarial (doc. 51).

A.N.T.T., Leitura Nova, livro 61 (livro das pazes), 21v.-22r.

\section{2}

\section{4, julio, 18. Olivenza.}

Martim Vicente de Villalobos, caballero, corregidor en la comarca entre los ríos Tajo y Guadiana, comunica al concejo castellano de Alconchel que va a realizar un apeo (inquirição) por orden de D. Afonso $V$ de Portugal para solucionar las disputas fronterizas con Olivenza (Portugal).

B.- Pergamino, folio, portugués. Inserto en un documento notarial (doc. 43) que a su vez está inserto en otro documento notarial (doc. 51).

A.N.T.T., Leitura Nova, livro 61 (livro das pazes), 22r.-22v. 


\section{3}

1454, julio, 6-23. Redondo-Olivenza.

Martim Vicente de Villalobos, caballero, corregidor en la comarca entre los ríos Tajo y Guadiana, procurador de D. Afonso $V$ de Portugal, realiza un apeo (inquirição) para solucionar las disputas fronterizas de Olivenza (Portugal) con Barcarrota, Figueira y Alconchel (Portugal). Incluye inserto el contenido de la orden dada por D. Duarte I de Portugal con data en Viseu el 24 de marzo de 1454 (doc. 38), las comunicación al concejo de Barcarrota, datada en Olivenza el 16 de julio de 1454 (doc. 39), y su respuesta, datada en Barcarrota el 27 de julio de 1454 (doc. 40), y las comunicaciones a los concejos de Figueira y Alconchel, datadas en Olivenza el 18 de julio de 1454 (docs. 41 y 42).

B.- Pergamino, folio, portugués. Inserto en otro documento notarial (doc. 51).

A.N.T.T., Leitura Nova, livro 61 (livro das pazes), 20v.-27v.

1466, julio, 21. Olivenza.

Pedro Machado, bachiller en leyes, del desembargo del rey, y oidor en la comarca entre los ríos Tajo y Guadiana, y más allá del Guadiana, Gastom López, juez en Olivenza, Lourenço Vieira, vereador, y otros hombres de la villa de Olivenza, acuerdan con Juan de Badajoz, alcalde mayor en Barcarrota, Juan Gonçalvez, alcalde en Barcarrota, y otros hombres de la villa de Barcarrota y Badajoz, realizar un apeo (inquirição) para solucionar las disputas fronterizas entre Olivenza (Portugal) y Barcarrota (Castilla).

B.- Pergamino, folio, portugués. Inserto en un documento notarial (doc. 51).

A.N.T.T., Leitura Nova, livro 61 (livro das pazes), 27v.-35r.

\section{5}

1466, agosto, 6. Estremoz.

D. Afonso $V$ de Portugal ordena a Martim Afonso de Melo, fronteiro de la comarca de Olivenza, que realice un apeo (inquirição) para solucionar las disputas fronterizas con Olivenza (Portugal) con Barcarrota, Alconchel y Figueira (Castilla).

B.- Pergamino, folio, portugués. Inserto en un documento notarial (doc. 50) que a su vez está inserto en otro documento notarial (doc. 51).

A.N.T.T., Leitura Nova, livro 61 (livro das pazes), 37r. 


\section{6}

\section{6, agosto, 18. Olivenza}

Martim Afonso de Melo, fronteiro de la comarca de Olivenza, comunica al concejo castellano de Barcarrota que va a realizar un apeo (inquirição) por orden de D. Afonso V de Portugal para solucionar las disputas fronterizas con Olivenza (Portugal).

B.- Pergamino, folio, portugués. Inserto en un documento notarial (doc. 50) que a su vez está inserto en otro documento notarial (doc. 51).

A.N.T.T., Leitura Nova, livro 61 (livro das pazes), 35v.-36r.

\section{6, agosto, 19. Olivenza}

Martim Afonso de Melo, fronteiro de la comarca de Olivenza, comunica al concejo castellano de Badajoz que va a realizar un apeo (inquirição) por orden de D. Afonso V de Portugal para solucionar las disputas fronterizas con Olivenza (Portugal).

B.- Pergamino, folio, portugués. Inserto en un documento notarial (doc. 50) que a su vez está inserto en otro documento notarial (doc. 51).

A.N.T.T., Leitura Nova, livro 61 (livro das pazes), 36r.-37r.

\section{8}

\section{6, agosto, 19. Évora}

D. Afonso $V$ de Portugal da instrucciones a Martim Afonso de Melo, fronteiro de la comarca de Olivenza, sobre la investigación (inquirição) que le ordenó realizar para solucionar las disputas fronterizas con Olivenza (Portugal) con Barcarrota, Alconchel y Figueira (Castilla).

B.- Pergamino, folio, portugués. Inserto en un documento notarial (doc. 50) que a su vez está inserto en otro documento notarial (doc. 51).

A.N.T.T., Leitura Nova, livro 61 (livro das pazes), 38v.-39r.

\section{9}

\section{6, septiembre, 9. Évora}

D. Afonso $V$ de Portugal da instrucciones a Martim Afonso de Melo, fronteiro de la comarca de Olivenza, sobre la investigación (inquirição) que le ordenó realizar para solucionar las disputas fronterizas con Olivenza (Portugal) con Barcarrota, Alconchel y Figueira (Castilla).

B.- Pergamino, folio, portugués. Inserto en un documento notarial (doc. 50) que a su vez está inserto en otro documento notarial (doc. 51).

A.N.T.T., Leitura Nova, livro 61 (livro das pazes), 39r.-39v. 
1466, agosto, 18 - noviembre, 22. Olivenza.

Martim Afonso de Melo, fronteiro de la comarca de Olivenza, y sus hijos Ruy de Melo, Manuel de Melo, con todo el concejo de Olivenza, realiza un apeo (inquirição) por orden de D. Afonso $V$ de Portugal para solucionar las disputas fronterizas con Olivenza (Portugal) con Barcarrota, Alconchel y Figueira (Castilla). Incluye inserto el contenido de la orden dada por D. Duarte I de Portugal con data en Estremoz el 6 de agosto de 1466 (doc. 45), la comunicación al concejo de Barcarrota, datada en Olivenza el 18 de agosto de 1466 (doc. 46) y al concejo de Badajoz, datada en Olivenza el 19 de agosto de 1466 (doc. 47), y dos instrucciones sobre el proceso dadas por Alfonso V, una datada en Évora el 19 de agosto de 1466 (doc. 48) y otra data en Évora el 9 de septiembre de 1466 (doc. 49).

B.- Pergamino, folio, portugués. Inserto en un documento notarial (doc. 51).

A.N.T.T., Leitura Nova, livro 61 (livro das pazes), 35r.-40v.

\section{1}

[1466, noviembre, 22 - 1471, agosto, 24] $]^{36}$

D. Afonso V ordena la realización de dos copias que recopilen todos los documentos referentes a las disputas fronterizas entre Olivenza (Portugal), y Badajoz, Barcarrota, Alconchel y Figueira (Castilla), una de ellas para el Arquivo Real de la Torre do Tombo y otra para el concejo de Olivenza. Incluye inserto el contenido de cinco procesos de investigación, el primero datado en Olivenza el 9 de marzo de 1353 (doc. 27), el segundo datado entre Barcarrota y Olivenza el 6 de abril de 1435 (doc. 36), el tercero y cuarto datados en Olivenza el 21 de julio de 1466 (doc. 43 y 44), y el quinto datado en Olivenza entre los meses de agosto y noviembre de 1466 (doc. 50); y el documento de nombramiento por parte de D. Afonso $V$ de Portugal de un fronteiro en la comarca de Olivenza, datado en Santarém el 15 de abril de 1449 (doc. 37).

A.- Pergamino, folio, portugués.

A.N.T.T., Feitos da Coroa, Núcleo Antigo 310 (Tumbos e demarcações de Olivença, Reino de Portugal, e Badajoz, Vila Noca de Barca Rota, Figueira e Alconchel, do Reino de Castela).

B.- Pergamino, folio, portugués.

A.N.T.T., Leitura Nova, livro 61 (livro das pazes), 1r.-40v.

${ }^{36}$ El documento carece de data crónica, se puede acotar entre el 22 de noviembre de 1466 , fecha en que está datado el último de los documentos insertos, y el 24 de agosto 1471, fecha de la batalla de Arzila que significa que el monarca cambia el título de "senhor de Alcácer em Africa" que aparece en el documento, por el de "senhor d'Aquém e d'Além-Mar em Africa". S. A. GOMES, D. Afonso $V$, Lisboa, 2006. 
1480, marzo, 6. Toledo.

Los Reyes Católicos ratifican las paces acordadas con D. João II de Portugal poniendo fin a la Guerra de Sucesión Castellana (1475-1479). En ellas se establece que Portugal reconoce los derechos castellanos sobre las Islas Canarias y que Castilla renuncia a los derechos portugueses sobre Guinea.

A.- Pergamino, folio, castellano.

A.N.T.T., Gavetas da Torre do Tombo, gaveta XVII, maço 6, documento 16.

B.- Pergamino, folio, castellano.

A.N.T.T., Leitura Nova, livro 61 (livro das pazes), 113r.-140v.

Edt.: J. S. SILVA, Collecçam do documentos com que se authorizam as memorias para a vida del Rey D. João I, vol. IV, pp. 270-358 (36).- F. GARDINER DAVENPORT, European Treaties..., vol. I, pp. 33-48.- As gavetas da Torre do Tombo..., vol. IX, pp. 500-501 (4555).- L. A. FONSECA, y J.M. RUIZ ASENCIO, Corpus documental del Tratado de Tordesillas, pp. 68 (29).

\section{3}

\section{5, febrero, 26. Almeirim.}

D. Manuel I de Portugal ratifica las paces acordadas entre Alfonso de Alburquerque y el rey de Calicut tras el fallido intento de invasión de las tropas portuguesas, establecen relaciones diplomáticas y comerciales.

B.- Pergamino, folio, portugués.

A.N.T.T., Leitura Nova, livro 61 (livro das pazes), 108v.-111v.

Edt.: J. F. J. BIKER, Collecção de tratados e concertos de pazes que o estado da India portugueza fez com os reis e senhores com quem teve relações nas partes da Asia e Africa Oriental desde o principio da conquista até ao fim do seculo XVIII, vol. I, Lisboa, 1881, pp. 28-33. 